\title{
O PROCESSO DE GESTÃO DE DOCUMENTOS DE IMAGENS EM MOVIMENTO EM EMISSORAS DE TELEVISÃO
}

\section{A TELEVISION STATION MANAGEMENT PROCESS OF MOVING IMAGE DOCUMENTS}

\author{
Aline Queiroz Lopesa \\ Adriana Bogliolo Sirihal Duarte ${ }^{b}$ \\ Alessandro Ferreira Costac
}

\begin{abstract}
RESUMO
Introdução: Os acervos de imagens televisivas são organizados e armazenados em centros de documentação, bancos de imagens ou arquivos de imagens. Gerenciar as imagens, tornando-as rapidamente disponíveis aos seus usuários internos, repórteres ou produtores de programas televisivos, é uma atividade que requer cada vez mais especificidades e vem desafiando profissionais da área. Objetivo: Investigar como é realizado o trabalho em um centro de documentação de imagens em movimento. Metodologia: Relacionar o fazer empírico com a teoria, de modo a buscar reflexões e contribuições para o aprimoramento dos processos, tendo por referência a observação participante no centro de documentação de imagens em movimento da Rede XXXXXX de Televisão, filial Belo Horizonte, Minas Gerais, Brasil. Resultados: A partir dos dados coletados, verificou-se não haver um consenso na nomenclatura adotada para o setor, bem como na seleção do profissional que ali atua. Conclusões: Aos processos investigados durante a observação participante, consideramos que o trabalho no centro de documentação de imagens é um processo contínuo e que não faz sentido se pensar separadamente as etapas de seleção, descrição, indexação e pesquisa, amparados pela teoria arquivística.
\end{abstract}

Descritores: Centro de documentação. Arquivo de imagens em movimento. Arquivo televisivo

\footnotetext{
a Mestre em Ciência da Informação e Bacharel em Biblioteconomia pela Escola de Ciência da Informação da Universidade Federal de Minas Gerais. Atua como bibliotecária do Centro de Documentação da Rede Globo Minas de Televisão. E-mail: aline_ql@yahoo.com.br

b Doutorado em Ciência da Informação pela também UFMG. Professora do Departamento de Teoria e Gestão da Informação da Escola de Ciência da Informação (UFMG). E-mail: adrianabsd@gmail.com

c Doutorado em Ciência da Informação pela Universidade Federal de Minas Gerais (UFMG). Professor do Departamento de Teoria e Gestão da Informação da Escola de Ciência da Informação (UFMG). E-mail: prof.alessandrocosta@gmail.com
} 


\section{INTRODUÇÃO}

O trabalho realizado diariamente em um Centro de Documentação Cedoc - que guarda conteúdos de imagens em movimento, produzidos por uma emissora de televisão, é o eixo discursivo do presente trabalho. A partir da pesquisa de mestrado "Reflexões arquivísticas no processo de gestão de documentos de imagens em movimento produzidos e/ou recolhidos em virtude da atividade fim de uma emissora de televisão" (LOPES, 2016), vinculada ao Programa de Pós-Graduação em Ciência da Informação da Escola de Ciência da Informação da UFMG, relacionando a teoria de arquivos, imagens em movimento e a metodologia de observação participante no contexto profissional de um Centro de Documentação de uma emissora de televisão; surgem os questionamentos que norteiam as discussões e reflexões apresentadas no texto.

Após o levantamento das ações realizadas diariamente em um Cedoc, buscou-se relacionar o trabalho realizado com conceitos, especialmente da arquivologia, no intuito de provocar reflexões sobre a melhor forma de trazer os princípios da ciência para o melhoramento das atividades lá desenvolvidas.

Para esta pesquisa, usou-se a expressão imagens em movimento em substituição à palavra audiovisual, exceto nas citações diretas. Essa escolha baseou-se nas recomendações para a salvaguarda e preservação de imagens em movimento da Organização das Nações Unidas para Educação, Ciência e Cultura (UNESCO), do ano de 19801 .

Assim, o objetivo desta pesquisa consiste em descrever os procedimentos realizados nos arquivos de imagens em movimento, provenientes da Rede XXXXX de Televisão, filial Belo Horizonte, e explicitar reflexões acerca da rotina de trabalho desses espaços, considerando principalmente as contribuições do referencial teórico da Arquivologia. Evidenciamos que em respeito aos procedimentos institucionais da Organização onde o presente trabalho fora realizado e aprovado pelas

\footnotetext{
1 UNESCO. Recomendación sobre la Salvaguardia y la Conservación de las Imágenes en Movimiento. 1980. Disponível em: <http://portal.unesco.org/es/ev.phpURL_ID=13139\&URL_DO=DO_TOPIC\&URL_SECTION=201.html>. Acesso em: 05 mar. 2016.
} 
instâncias acadêmicas competentes, não podemos aqui registrar/disponibilizar o seu nome.

A vivência prática naquele espaço de trabalho, por já se tratar ele uma rotina de atividades vivenciadas pela autora da pesquisa de Mestrado aqui relatada, foi utilizada como subsídio para observar os fenômenos que pertencem a esses acervos, no intuito de investigar as características que são pertinentes aos acervos de imagens em movimento produzidos e/ou recolhidos em virtude da atividade fim de uma emissora de televisão.

\section{ARQUIVOS, DOCUMENTOS E FUNDOS}

Segundo Schellenberg (2006), a definição do termo arquivo aparece na literatura de diversas formas e não existe uma definição final que deva ser aceita como sendo a melhor. $O$ autor ressalta ainda que cada país pode modificar uma definição de acordo com suas necessidades e especificidades e que essa definição deve atender à realidade. O Dicionário Brasileiro de Terminologia Arquivística traz a definição de arquivo como um "[...] conjunto de documentos produzidos e acumulados por uma entidade coletiva, pública ou privada, pessoa ou família, no desempenho de suas atividades, independentemente da natureza do suporte" (BRASIL, 2004, p. 27).

O termo documento, nesse mesmo dicionário, é definido como "unidade de registro de informações, qualquer que seja o suporte ou formato" (BRASIL, 2004, p. 73). Bellotto explica que os documentos de arquivo são aqueles

[...] produzidos por uma entidade pública ou privada ou por uma família ou pessoa no transcurso das funções que justificam sua existência como tal, guardando esses documentos relações orgânicas entre si. Surgem, pois, por motivos funcionais administrativos e legais. Tratam sobretudo de provar, de testemunhar alguma coisa. Sua apresentação pode ser manuscrita, impressa ou audiovisual; são em geral exemplares únicos e sua gama é variadíssima, assim como sua forma e suporte (BELLOTTO, 2006, p. 37). 
Assim, as características primordiais dos arquivos se relacionam com os motivos que levaram a sua existência e com as razões que levam à sua preservação.

A organicidade das informações/documentos é uma das características que distinguem $o$ arquivo de outros espaços. Em contrapartida, temos a informação não orgânica que "[...] existe muitas vezes nos locais de trabalho mas igualmente na biblioteca ou no centro de documentação, sob a forma de publicações, de bancos de dados ou de dossiers temáticos, etc." (ROUSSEAU; COUTURE, 1998, p. 65).

A utilização da informação orgânica se dá pelo seu valor primário ou pelo seu valor secundário. Por valor primário entende-se "[...] valor atribuído a documento em função do interesse que possa ter para a entidade produtora ${ }^{2}$, levando-se em conta a sua utilidade para fins administrativos, legais e fiscais" (BRASIL, 2004, p. 171). O valor secundário é o "[...] valor atribuído a um documento em função do interesse que possa ter para a entidade produtora e outros usuários, tendo em vista a sua utilidade para fins diferentes daqueles para os quais foi originalmente produzidos" (BRASIL, 2004, p. 172).

A arquivística tem um princípio aplicável em todos os momentos em que suas intervenções são realizadas: o princípio da proveniência. Segundo o Dicionário Brasileiro de Terminologia Arquivística, ele corresponde ao "princípio básico da arquivologia segundo o qual o arquivo produzido por uma entidade coletiva, pessoa ou família não dever ser misturado aos de outras entidades produtoras" (BRASIL, 2004, p. 127).

Schellenberg ressalta que segundo o princípio de proveniência

Os arquivos devem ser arranjados de tal maneira que a organização e funções que os produziram neles se reflitam, unidade administrativa por unidade, subunidade por subunidade e série por série de documentos (SCHELLENBERG, 2006, p. 161).

\footnotetext{
2 Entende-se como sendo a entidade coletiva, pessoa ou família identificada como geradora de arquivo. Também chamada produtor. Cf. Brasil, 2004. Disponível em: <http://www.arquivonacional.gov.br/Media/Dicion\%20Term\%20Arquiv.pdf>. Acesso em: 24 de abr. de 2016.
} 
A aplicação do princípio de proveniência se faz necessária para que o fundo de arquivo exista.

O respeito deste princípio, na organização e no tratamento dos arquivos qualquer que seja a sua origem, idade, natureza ou suporte, garante a constituição e a plena existência da unidade de base em arquivística, a saber, o fundo de arquivo. O princípio da proveniência e o seu resultado, o fundo de arquivo, impõem-se à arquivística, uma vez que esta tem por objectivo (sic) gerir o conjunto de informações geradas por um organismo ou por uma pessoa no âmbito das actividades ( $\mathrm{sic}$ ) ligadas à missão, ao mandato e ao funcionamento do dito organismo ou ao funcionamento e à vida da referida pessoa. Pense-se na criação, avaliação, aquisição, classificação, descrição, comunicação ou na conservação dos arquivos: todas as intervenções do arquivista devem ocorrer sob o signo do princípio da proveniência e, à partida, do reconhecimento do fundo de arquivo como unidade central das operações arquivísticas." (ROUSSEAU; COUTURE, 1998, p. 79).

Como fundo entende-se os "[...] conjuntos de documentos de uma mesma proveniência" (ROUSSEAU; COUTURE, 1998, p. 87) e estes podem ser abertos ou fechados. No fundo aberto temos um conjunto de arquivos que continuará a receber documentos, o contrário do fundo fechado, que é um conjunto de arquivos que não receberá mais documentos, exceto em alguns casos, como por exemplo se ocorrer a descoberta de cartas de um determinado personagem após sua morte e estas tiverem sido escritas em datas de quando o fundo ainda era aberto.

Bellotto (2006, p. 128) define como fundo

O conjunto de documentos produzidos e/ou acumulados por determinada entidade pública ou privada, pessoa ou família, no exercício de suas funções e atividades, guardando entre si relações orgânicas, e que são preservados como prova ou testemunho legal e/ou cultural, não devendo ser mesclado a documentos de outro conjunto, gerado por outra instituição, mesmo que este, por quaisquer razões, the seja afim.

Para se estabelecer os fundos em um arquivo é crucial o entendimento das estruturas administrativas da entidade, tanto as do presente quanto as do passado, e isso engloba conhecer "[...] o ato de criação, a evolução, a competência e as atribuições de cada organismo governamental ou 
organização privada, e qual sua posição no organograma administrativo" (BELLOTTO, 2006, p. 33).

Com o crescimento da criação de documentos, causado principalmente pela democratização dos meios de reprodução da informação, tornou-se necessário a criação de uma designação que intermediasse o período ativo e inativo dos arquivos. Segundo Rousseau e Couture, (1998) o termo ativo é usado para "[...] designar os documentos que têm a taxa de utilização mais alta" e o inativo, ou definitivo, para "[...] designar os documentos que deixaram de ter valor previsível no plano administrativo" (ROUSSEAU; COUTURE, 1998, p. 112). Surge então o termo semiativo, que teve origem por questões de espaços e de ordem econômica, já que:

Esse período intermédio devia permitir evitar, por um lado, que se guardassem documentos durante demasiado tempo nos locais da administração de origem, cujos espaços, já de si restritos, se viam ameaçados por uma quantidade inquietante de documentos e, por outro, que se transferissem prematuramente demasiados documentos que deviam ser conservados de modo permanente (ROUSSEAU; COUTURE, 1998, p. 112).

Rousseau e Couture, após discussões com vários profissionais, propõem uma designação terminológica classificando os arquivos correntes, intermediários e definitivos (permanentes), sendo "arquivos correntes, que são constituídos por documentos ativos, arquivos intermédios, compostos por documentos semiativos e arquivos definitivos, que agrupam os documentos inativos com valor de testemunho" (ROUSSEAU; COUTURE, 1998, p. 113). Os autores esclarecem que

Esses documentos, inativos para a pessoa moral ou física que os produziu, são perfeitamente ativos para o utilizador interessado pelo valor de testemunho que eles encerram. Parece, pois, correto afirmar que existe um período de inatividade ao longo do qual dos documentos deixam de ter valor previsível para o produtor. Os documentos desse período são documentos inativos, dos quais alguns são eliminados, não havendo razões para se guardarem, enquanto outros são conservados pelo seu valor de testemunho. Para estes, a que alguns chama 'arquivos históricos', propomos o termo 'arquivos definitivos' [...] (ROUSSEAU; COUTURE, 1998, p. 114). 
No que se refere ao ciclo de vida dos documentos administrativos, Bellotto afirma que estes compreendem três idades.

A primeira é a dos arquivos correntes, nos quais se abrigam os documentos durante seu uso funcional, administrativo, jurídico; sua tramitação legal; sua utilização ligada às razões pelas quais foram criados. A permanência de tais documentos nesse tipo de arquivo depende de sua tipologia/função e, principalmente, de sua vigência [...] (BELLOTTO, 2006, p. 24).

Os arquivos intermediários compõem a segunda fase que "[...] é aquela em que os papéis já ultrapassaram seu prazo de validade jurídicoadministrativo, mas ainda podem ser utilizados pelo produtor" (BELLOTTO, 2006, p. 24). É na fase intermediária que os arquivos são submetidos às tabelas de temporalidade e estas irão determinar por quanto tempo o documento precisa ser mantido naquele arquivo, considerando sua tipologia e função.

Quanto melhor o arquivo intermediário cumprir sua atividade de preservação dos documentos permanentes e de eliminação criteriosa do material inservível, tanto melhor serão as tarefas da custódia e da disseminação da informação (BELLOTTO, 2006, p. 32).

A tabela de temporalidade, segundo o Dicionário brasileiro de terminologia arquivística, é:

Um instrumento de destinação, aprovado pela autoridade competente, que determina prazos e condições de guarda tendo em vista a transparência, recolhimento, descarte, ou eliminação de documentos (BRASIL, 2004, p. 150).

Bellotto considera que o arquivo permanente compreende a terceira fase do ciclo de vida dos documentos. Para o Arquivo Nacional, o arquivo permanente é um "[...] conjunto de documentos preservados em caráter definitivo em função do seu valor" (BRASIL, 2004, p. 34). Os arquivos de valor permanente possuem um valor além da proteção do patrimônio documental, "[...] a custódia não se restringe a 'velar' pelo patrimônio documental. Ultrapassado totalmente o uso primário, iniciam-se os usos científicos, social e cultural dos documentos" (BELLOTTO, 2006, p. 24). 
O entendimento aprofundado dessas questões se faz necessário para uma visão crítica sobre os procedimentos que são utilizados nos arquivos e, principalmente, nos centros de documentação.

\section{CENTROS DE DOCUMENTAÇÃO}

Um centro de documentação pode ser considerado uma entidade híbrida, um espaço misto de arquivo, biblioteca e/ou museu, mas que não se identifica com nenhuma delas. "Reúne, por compra, doação ou permuta, documentos únicos ou múltiplos de origens diversas (sob a forma de originais ou cópias) e/ou referências sobre uma área específica da atividade humana" (TESSITORE, 2003, p. 14).

Segundo Tessitore, as principais características dos Centros de documentação são:

Possuir documentos arquivísticos, bibliográficos e/ou museológicos, constituindo conjuntos orgânicos (fundos de arquivo) ou reunidos artificialmente, sob a forma de coleções, em torno de seu conteúdo; ser um órgão colecionador e/ou referenciador; ter acervo constituído por documentos únicos ou múltiplos, produzidos por diversas fontes geradoras; possuir como finalidade o oferecimento da informação cultural, científica ou social especializada; realizar o processamento técnico de seu acervo, segundo a natureza do material que custodia (TESSITORE, 2003, p. 14).

Essas características nos fornecem indícios de que pode haver uma confusão em relação à utilização do termo em alguns espaços, seja pela amplitude da terminologia, seja pelo simples fato do desconhecimento.

A autora Tessitore afirma que os processos de aquisição, armazenamento e processamento técnico desse tipo de acervo tem características das três áreas: biblioteconomia, arquivologia e/ou museologia, pois apresentam uma diversidade de materiais. Para a autora essa diversidade é, "ao lado da especialização temática, a marca distintiva dos Centros de Documentação, e que está presente também em suas atividades referenciadoras" (TESSITORE, 2003, p. 15). Porém, atualmente os procedimentos arquivísticos estão predominando a atuação nesses espaços, 
Essa tendência se justifica pelo fato de os arquivos serem a expressão material da atuação cotidiana de pessoas e entidades, nos diferentes campos, que se tornaram objeto de um repensar por parte dos mais variados segmentos sociais. (TESSITORE, 2003, p. 15).

Reforçando o entendimento do que seriam os espaços nomeados de Centro de Documentação, seguem as competências gerais que ele deve possuir:

Reunir, custodiar e preservar documentos de valor permanente e referências documentais úteis ao ensino e à pesquisa em sua área de especialização; estabelecer uma política de preservação de seu acervo; disponibilizar seu acervo e as referências coletadas aos usuários definidos como seu público; divulgar seu acervo, suas referências e seus serviços ao público especializado; promover intercâmbio com entidades afins (TESSITORE, 2003, p. 15).

Percebe-se a complexidade desses espaços, não somente por sua definição tão abrangente, como também pela possibilidade de não haver clareza em relação às competências que são primordiais aos Cedocs.

O dia a dia nos Centros de Documentação exige a tomada de decisões, e estas precisam estar embasadas em uma política bem definida e entendida por toda a equipe que atua nesses espaços e pelos usuários que dele fazem uso. Assim, uma gestão eficiente reflete no bom funcionamento dessas unidades informacionais.

A gestão é um elemento universal do mundo moderno, que aplica métodos e técnicas com o intuito de alcançar objetivos em um cenário complexo que envolve tomada de decisão, organização, uso da informação e coordenação de múltiplas atividades (ALVES; DUARTE, 2015, p. 42).

Tessitore ressalta que nem todos os Centros de Documentação possuem o objetivo de preservação da memória ou mesmo pesquisa histórica. Para a autora, muitos desses espaços "[...] estão vinculados à pesquisa em outras áreas ou à produção e prestação de serviços" (TESSITORE, 2003, p. 18). E ainda, o Cedoc poderá possuir um acervo de natureza distinta, tais como:

Inf. Inf., Londrina, v. 23, n. 2, p. $340-371$, maio/ago. 2018 http://www.uel.br/revistas/informacao 
Fundos de arquivo: conjuntos de documentos acumulados no exercício das funções de entidades ou pessoas (um arquivo que passou a conviver com outros semelhantes ao ser transferido para o Centro de Documentação); coleções: conjuntos de documentos reunidos, de forma artificial, em torno de temas, funções, entidades, pessoas ou até mesmo de um tipo ou gênero de documento; material hemerográfico: jornais, revistas e boletins; material bibliográfico: livros, teses e folhetos; objetos tridimensionais: de acordo com a área do Centro; bancos de dados: sobre temas específicos, referências sobre as atividades e o acervo de entidades afins (TESSITORE, 2003, p. 18).

Muitas vezes esses dois termos - Arquivo e Centro de Documentação são utilizados como se não houvesse uma distinção entre eles. Para Rayo, "a documentação sobre a televisão tem finalidade eminentemente prática, proporcionando tanto informação como os materiais necessários para preparar a programação, isto é, uma ferramenta sobre cadeia de produção" (LOPEZ DE QUINTANA, 2000, apud RAYO, 2004, p. 67, tradução nossa).

Segundo Rayo, o Centro de Documentação de televisão condensa toda a tradição documental e suas funções correspondem as desempenhadas pelos Arquivos, Bibliotecas e Centros de Documentação em geral. A autora divide o trabalho dos Centros de Documentação de televisão em três funções:

a) Função arquivística: o Centro de documentação conserva o material audiovisual tanto em função do seu valor econômico quanto de seu valor documental para a história da própria empresa e cria o arquivo.

b) Função bibliotecária: o Centro de documentação atende as necessidades de informação de seus usuários.

c) Função documental: o Centro de documentação colabora com a difusão do material tanto em sua vertente interna (reutilização) como na externa (exploração comercial) (RAYO, 2004, p. 71, tradução nossa).

A criação de um arquivo de imagens em movimento, segundo Rayo (2004, p. 72) é o principal objetivo do Centro de documentação ao se considerar sua função arquivística. Para isso, é necessário conhecer os objetivos das empresas, os recursos disponíveis para sua criação e o estabelecimento de parâmetros adequados para a seleção do material do Arquivo, que podem ter valor econômico e valor patrimonial, tanto para a história da empresa como para a sociedade em geral. Na função de Biblioteca, 
- Cedoc atua como memória da instituição ou empresa, oferecendo a seus usuários a informação necessária à elaboração da programação, para quaisquer profissional da cadeia produtiva, sejam eles produtores, editores e etc. O usuário deve ter ao seu alcance diversas fontes de pesquisa de imagens em movimento, escrita, gráfica e sonora, assim como evidencia Rayo (2004, p. 74).

A outra função que se deve realizar num Centro de documentação de televisão é a de colaborar com a difusão do material de imagens em movimento tanto em sua vertente interna (reutilização do material) como em sua vertente externa (exploração comercial do arquivo). O objetivo principal do que estamos chamando de função documental é "[...] difundir, dar a conocer lo que sin la presencia del centro no sería conocido" (LÓPES YEPES, 1992, apud RAYO, 2004, p. 82). Para alcançar esse objetivo é necessário um tratamento documental do material (seleção e análise) o que permite disponibilizar aos usuários o melhor material em um menor tempo possível (RAYO, 2004, p. 82).

$O$ entendimento do que realmente venha a ser um centro de documentação é necessário para se lançar um olhar crítico sobre a definição desses espaços onde estão armazenados os documentos de imagens em movimento produzidos por uma emissora de televisão. Assim, o olhar do profissional que convive diariamente com esse universo permite identificar vestígios que demonstram a necessidade de se repensar a denominação desses espaços.

\section{AS IMAGENS EM MOVIMENTO}

A definição de imagens em movimento pela Organização das Nações Unidas para Educação, Ciência e Cultura (UNESCO), em suas recomendações para a salvaguarda e preservação desse tipo de material, do ano de 1980, corresponde a

Qualquer série de imagens registradas em um suporte (independentemente do método de registro do mesmo e da natureza do suporte - por exemplo películas, fita, disco, etc. utilizados no passado ou atualmente para gravação com ou sem acompanhamento sonoro que, ao ser projetada dão uma 
impressão de movimento e são destinadas à comunicação ou à distribuição ao público ou são feitas para fins de documentação; é considerada como compreendendo, entre outros elementos, as seguintes categorias:

i) produções cinematográficas (tal como películas de longa metragem, curta metragem, de divulgação científica, documentários e cinejornais, filmes de animação e educativos); ii) produções televisivas realizadas por ou para os organismos de radiodifusão;

iii) produções videográficas (contidas em videogramas) com exceção das mencionadas nas alíneas i) e ii) (UNESCO, 1980, tradução nossa).

Em seu Manual de Catalogação de Imagem em Movimento, de 2016, a Federação Internacional de Arquivos Fílmicos (FIAF) define imagem em movimento trazendo alguns aspectos contemporâneos:

\begin{abstract}
Imagens em movimento incluem uma série de materiais sobre os quais seguências de imagens visuais foram gravadas ou registradas e que criam a ilusão de movimento quando projetadas, difundidas ou reproduzidas (por meio de um projetor, aparelho de televisão, computador, software ou dispositivos equivalentes). Tais imagens podem ou não ser acompanhadas de som. A definição inclui imagens em movimentos de todos os tipos, por exemplo, apresentações, curtas, noticiários, trailers, cenas não editadas, testes de tela, documentários educativos e de treinamento, produções experimentais ou independentes, filmes ou vídeos de estudo, filmes caseiros, materiais inéditos, transmissões de televisão, comerciais, anúncios locais, performances gravadas de concertos, balés, peças de teatro, imagens de circuito interno etc. Elas englobam tanto a ação ao vivo quanto animação e incluem todos os formatos analógicos e digitais (FIAF, 2016, p. 5, tradução nossa).
\end{abstract}

Nas recomendações da UNESCO as imagens em movimento são consideradas "uma expressão da personalidade e cultura de um povo e que, devido ao seu valor educativo, cultural, artístico, científico e histórico, fazem parte do patrimônio cultural de uma nação" (UNESCO, 1980, tradução nossa). Pensar em sua preservação é pensar em ações efetivas que possam garantir o seu acesso.

O acesso facilitado às diversas tecnologias possibilita que as imagens em movimento sejam hoje produzidas em qualquer lugar, o tempo todo. Essa realidade reforça, ainda mais, grandes questionamentos e desafios para os responsáveis pelo gerenciamento desses conteúdos que garantam o acesso e 
reutilização futuros (FIAT/IFTA, 2016). O debate e compartilhamento do fazer em arquivos responsáveis pela guarda desses tipos de documentos é de extrema importância para o desenvolvimento de políticas nesses espaços.

\section{O CENÁRIO DOS ARQUIVOS TELEVISIVOS EM BELO HORIZONTE}

Belo Horizonte, a capital mineira, conta hoje com várias emissoras de televisão e canais universitários que produzem diariamente um vasto material de imagem em movimento. Dentre as emissoras encontram-se a Globo Minas, Record Minas, Band Minas, Rede Minas, Rede Super, TV Alterosa e TV Horizonte.

Também é importante mencionar os canais universitários, como a Puc TV e a TV UFMG, que podem servir de laboratórios para os estudantes de jornalismo dessas instituições e, apesar de não terem um grande espaço nos índices de audiência, são fontes importantes de pesquisa e merecem atenção do nosso olhar, pois produzem um vasto material de imagens em movimento. Além disso, esses canais podem ter um caráter mais experimental, o que permite a oferta de conteúdos mais alternativos, se comparados à produção de canais comerciais.

Em um levantamento, realizado no mês de maio de 2015, a situação das emissoras de TV de Belo Horizonte se apresentava da seguinte forma:

Quadro 1 - Emissoras/canais universitários de televisão de Belo Horizonte e seus arquivos

\begin{tabular}{c|c|c|c|c|c}
\hline $\begin{array}{c}\text { Emissora/ } \\
\text { Canal } \\
\text { Universitário }\end{array}$ & $\begin{array}{c}\text { Nome do } \\
\text { Arquivo }\end{array}$ & $\begin{array}{c}\text { Tipo de } \\
\text { instituição }\end{array}$ & $\begin{array}{c}\text { Inauguração } \\
\text { do arquivo }\end{array}$ & $\begin{array}{c}\text { Formação dos } \\
\text { Profissionais }\end{array}$ & $\begin{array}{c}\text { Mídia de } \\
\text { armazenamento }\end{array}$ \\
\hline TV Horizonte & $\begin{array}{c}\text { Banco de } \\
\text { imagens }\end{array}$ & Privada & 1998 & $\begin{array}{c}\text { 2 funcionários } \\
\text { sem formação } \\
\text { específica }\end{array}$ & Fitas LTO \\
\hline Globo Minas & $\begin{array}{c}\text { Centro de } \\
\text { documentação - } \\
\text { CEDOC }\end{array}$ & Privada & 1996 & $\begin{array}{c}\text { 3biblioteconomia; } \\
\text { 2 Jornalismo; } \\
\text { 3editores } \\
\text { (História, Mídia); } \\
\text { 1 estagiário de } \\
\text { biblioteconomia }\end{array}$ & XDCAM e
\end{tabular}

Inf. Inf., Londrina, v. 23, n. 2, p. 340 - 371, maio/ago. 2018. 


\begin{tabular}{|c|c|c|c|c|c|}
\hline Record Minas & $\begin{array}{l}\text { Arquivo de } \\
\text { imagens }\end{array}$ & Privada & $\begin{array}{l}2007 \text { (e } \\
\text { outras } \\
\text { recuperadas } \\
\text { de um } \\
\text { incêndio que } \\
\text { atingiu o } \\
\text { arquivo) }\end{array}$ & $\begin{array}{c}1 \text { administração } \\
1 \text { direito } \\
1 \text { sem graduação }\end{array}$ & $\begin{array}{l}\text { Robô (porta de } \\
\text { entrada para até } \\
100 \text { discos, } \\
\text { sendo de } \\
\text { 2terabyte cada) }\end{array}$ \\
\hline Rede Minas & $\begin{array}{l}\text { Centro de } \\
\text { documentação } \\
\text { e Fitoteca }\end{array}$ & Pública & 1985 & $\begin{array}{c}\text { 1biblioteconomia; } \\
1 \text { jornalismo; } \\
4 \text { técnico de TV }\end{array}$ & $\begin{array}{l}9 \text { tipos de fitas } \\
\text { Arquivo digital } \\
\text { (Data Center- } \\
\text { MAN) }\end{array}$ \\
\hline Rede Super & Videoteca & Privada & 2000 & $\begin{array}{l}4 \text { funcionários, } \\
\text { sem formação } \\
\text { específica } \\
1 \text { menor aprendiz }\end{array}$ & DVD \\
\hline TV Alterosa & $\begin{array}{c}\text { Não há um } \\
\text { setor para } \\
\text { guarda e } \\
\text { organização do } \\
\text { material }\end{array}$ & Privada & - & $\begin{array}{c}\text { Auxiliar de } \\
\text { operações } \\
\text { jornalísticas }\end{array}$ & Servidor \\
\hline Band Minas & $\begin{array}{c}\text { Não há um } \\
\text { setor para } \\
\text { guarda e } \\
\text { organização do } \\
\text { material } \\
\text { existente }\end{array}$ & Privada & - & $\begin{array}{l}\text { Não existe um } \\
\text { profissional } \\
\text { responsável, } \\
\text { cada setor } \\
\text { armazena da sua } \\
\text { forma }\end{array}$ & $\begin{array}{l}\text { BETACAM, DVD } \\
\text { e servidor }\end{array}$ \\
\hline TV Puc Minas & $\begin{array}{c}\text { Centro de } \\
\text { Documentação }\end{array}$ & Educacional & - & 1 Jornalista & - \\
\hline TV UFMG & $\begin{array}{c}\text { Centro de } \\
\text { documentação }\end{array}$ & Educacional & 2011 & $\begin{array}{c}1 \text { letras e } \\
2 \text { estagiários da } \\
\text { biblioteconomia }\end{array}$ & $\begin{array}{l}\text { U-matic, Beta, } \\
\text { XDCAM e } \\
\text { formato digital }\end{array}$ \\
\hline
\end{tabular}

Fonte: Dados coletados e tabulados no decorrer da pesquisa de mestrado, entre os anos de 2015 e 2016.

Quanto à questão dos profissionais que atuam nos acervos pesquisados, percebe-se a existência de uma diversidade na formação dos mesmos e a falta do profissional bibliotecário ou arquivista em algumas das instituições pesquisadas. Neste contexto, questionamos: será que são as empresas que preferem profissionais de áreas distintas às dos bibliotecários e arquivistas ou será que são estes profissionais que não se mostram, não evidenciam a sua importância estratégica, não se fazem percebidos pela sociedade? No nosso entendimento, considerando a experiência vivenciada no 
período de pesquisa, o que temos é um mix dos dois pontos. Por um lado, as Organizações possuem pouco esclarecimento quanto à presença de profissionais capacitados ao trato de acervos documentais, nos mais diversos suportes. Por outro lado, aqueles profissionais precisam melhor pontuar os espaços de atuação, com o suporte de entidades de classe e da própria academia.

Já em relação à mídia de armazenamento das imagens, encontramos vários formatos de suportes. São eles: o DVD, Digital VersatileDisc; as fitas UMATIC formato de fita de vídeo analógica; fita BETACAM, formato de fita de vídeo analógica ou digital; o XDCAM, disco óptico para armazenamento de dados de vídeo digital; e o formatos digitais já armazenados em servidores, como o Data Center-MAN. Outra questão pertinente a ser abordada, é o tipo de mídia utilizado. O DVD (Digital VersatileDisc) é uma mídia muito frágil e o fato de um acervo ser constituído somente por esse suporte, traz grandes preocupações. A escolha dessa mídia se dá pelo baixo custo, porém, a curto e médio prazo, poderá custar a sobrevivência das imagens nele armazenadas. Assim, o arquivo de imagens em movimento da Rede Super, corre um risco maior de perder, a qualquer momento, imagens significativas de seu acervo. No caso da Globo Minas, o DVD foi utilizado como uma mídia emergencial para migrar as imagens que se encontravam em fitas U-MATIC (formato de fita de vídeo analógico). Atualmente, as imagens existentes nos DVDs já estão sendo migradas para XDCAM (disco óptico para armazenamento de dados de vídeo digital), uma mídia que possui um preço mais alto, contudo, oferece mais segurança e sua capacidade de armazenamento é maior que a do DVD.

A diversidade de mídias de armazenamento é percebida no arquivo da Rede Minas. Este possui nove tipos de fitas em seu acervo, além do arquivo digital. Tal característica pode trazer transtornos quando se considera que cada tipo de fita possui uma especificidade diferente, como por exemplo, formato e durabilidade, que variam de acordo com o modelo da fita, ou seja, o cuidado relacionado à obsolescência dos hardwares e softwares são ainda maiores.

É preocupante verificar que não existe a iniciativa de se criar um setor responsável pela organização dos arquivos televisivos, caso da Band Minas. 
Em entrevista com jornalistas da emissora, eles mencionaram que, no caso do material produzido atualmente, pelo esporte, por exemplo, são arquivados no servidor somente VTs e gols. Quando necessário rever algum programa na íntegra, recorrem a programas da internet, como o Youtube. Em relação à data inicial do material disponível, caso das Betas e DVDs existentes, fora informado que datam desde o início das atividades da emissora em Minas Gerais, nos anos de 1970. Assim, considerando a obsolescência e falta de um responsável pela migração das mídias, acredita-se que muito material já foi perdido.

As informações obtidas em relação à TV Alterosa são de que o material que foi produzido em película não existe mais e o que era gravado em UMATIC também se perdeu devido à reutilização das fitas, ou seja, realizavam a gravação de novas imagens em cima das já existentes. As imagens atuais são armazenadas em um servidor, mas não existe um setor responsável pela guarda dessas imagens. O material fica sob a responsabilidade de um auxiliar de operações jornalísticas, que normalmente é representado por um estudante de jornalismo ou um jornalista recém-formado. Este auxiliar faz a recuperação do material, quando solicitado pela produção ou editores.

O quadro também demonstra a recente preocupação das emissoras de televisão em organizar e preservar seus acervos de imagem. Isso indica sua pouca maturidade, e reforça a importância dos estudos na área, na busca de contribuir para uma melhor gestão dessas unidades de informação.

\section{O COTIDIANO DA GUARDA DE IMAGENS EM UMA EMISSORA}

Apresentam-se a seguir os resultados do vivenciamento prático referente à rotina de trabalho em um setor responsável pela guarda de imagens (em movimento e fixas) em uma emissora de televisão. Trata-se de uma empresa privada que tem sua programação exibida em um canal aberto. Apesar da empresa estar no mercado há mais de quarenta anos, o arquivo de imagem em movimento produzido pela emissora ganhou um espaço para sua guarda e gestão no ano de 1996 quando criou-se o Centro de Documentação com uma estrutura adequada para guarda e tratamento desse material. 
Desde sua criação oficial, em 1996, até a presente data, o profissional responsável pela gestão do Cedoc é um bibliotecário que, atualmente, além do estagiário de biblioteconomia, conta com mais sete profissionais em sua equipe: uma bibliotecária, três pesquisadores e três editores.

O dia a dia do profissional que está no mercado de trabalho, atuando em arquivos de imagens em movimento de televisão, é um desafio constante. É um campo repleto de questões a serem exploradas, assim como será evidenciado nas linhas que seguem. É importante salientar que os procedimentos citados a seguir fazem parte da realidade de um Centro de Documentação específico. Os mesmos não podem ser considerados um modelo a ser seguido, muito menos serem vistos como a forma mais correta de se realizar esse fluxo de trabalho. Também há de se considerar que no mercado de trabalho algumas terminologias podem ser incorporadas sem uma reflexão adequada de seu verdadeiro significado.

A rotina no Cedoc investigado perpassa pelo processo de seleção, descrição, indexação e pesquisa ou recuperação das imagens. Para a realização de cada uma dessas ações são necessários diversos procedimentos e, apesar de não haver uma política escrita, existe uma política consensual que rege a tomada de decisão em todos os momentos. O software utilizado para gestão de todo o acervo do Cedoc é o Registro e Recuperação de Documentos, ou RRD, como é chamado pelos profissionais que trabalham com ele. Este software não está disponível para comercialização no mercado, ele foi criado pela empresa para atender suas demandas específicas de armazenamento e organização dos documentos de imagens em movimento. A seguir, expõe-se sobre cada ação no fazer diário desse profissional.

\subsection{Seleção}

Imagine-se a construção de uma reportagem sobre a história das igrejas da cidade de Ouro Preto. O repórter e o cinegrafista têm a pauta em mãos e, a partir dela, a responsabilidade de produzirem texto e imagens que irão constituir o produto final: a reportagem. Porém, antes do produto final têm-se diversos documentos que são formados nesse processo. A pauta é importante 
fonte de informação, assim como as imagens que foram feitas e que não serão utilizadas para a reportagem, imagens essas chamadas de imagens brutas.

$\mathrm{Na}$ construção da reportagem, ou vídeo tape (VT), como também é chamado no ambiente jornalístico, serão utilizadas as melhores imagens das igrejas e, na maioria das vezes, são imagens mais curtas, editadas. Então, o que fazer com o restante das imagens produzidas? Essas imagens brutas são extremamente importantes na constituição do acervo televisivo, isso principalmente porque nem sempre é possível o deslocamento de toda uma equipe para a produção de um vt. Assim, é solicitado ao arquivo as imagens para ilustrarem o material que será produzido, e a preferência dos usuários é, na maioria das vezes, pela imagem bruta, que são imagens mais longas e permitem ao responsável pelo vt, o editor de imagem, um material mais rico de possibilidades. Percebe-se a importância da seleção na constituição do acervo do arquivo. Por seleção entende-se a "[...] operação intelectual que consiste em escolher, ao final de uma avaliação, os documentos que convém incorporar" (EDMONDSON, 2013, p. 161), ou seja, é nesse momento em que é feita a "separação dos documentos de valor permanente daqueles passíveis de eliminação, mediante critérios e técnicas previamente estabelecidos em tabela de temporalidade" (BRASIL, 2004, p. 152). O uso de critérios e técnicas bem definidos facilitará a tomada de decisão pelo profissional responsável por essa atividade.

A seleção de imagens deve ser criteriosa e exige muito do profissional que a realiza. Importante destacar a necessidade de uma aproximação do arquivo com os cinegrafistas que produzem essas imagens, e tornar uma obrigação a inserção de metadados ${ }^{3}$ no momento em que elas são produzidas.

Após a seleção das imagens a serem guardadas, estas são inseridas em um software de registro e recuperação de documentos. Feito isso, é o momento de descrever todas as imagens, ou, em uma linguagem também utilizada pelos profissionais da empresa pesquisada, fazer a sinopse de todo 0 documento.

3 Podem ser basicamente definidos como "dados que descrevem os dados", ou seja, são informações úteis para identificar, localizar, compreender e gerenciar os dados. Disponível em: <http://www.metadados.ibge.gov.br/consulta/default.aspx>. Acesso em: 30 jun. 2016. 


\subsection{Descrição}

A descrição corresponde ao "conjunto de procedimentos que leva em conta os elementos formais e de conteúdo dos documentos para elaboração de instrumentos de pesquisa" (BRASIL, 2004, p. 67). Apesar do termo sinopse ser utilizado como sinônimo de descrição na instituição pesquisada, ele possui definições distintas, pois é considerado como sendo

[...] ideias da nossa própria lavra, a defesa das nossas personagens, a expressão escrita da alma da história. Convém, pois, que seja um texto claro e fluido, que goze de uma boa redação. Mas seu estilo deve ser literalmente neutro, com a única intenção de descobrir o relato e sua capacidade de se converter em roteiro. Não é o lugar adequado para pretender fazer brilhar o estilo; e, embora deva ser atraente e sugestivo, sua qualidade mais determinante é a solidez (COMPARATO, 2000, p. 112).

Ainda segundo Comparato (2000, p. 120), uma sinopse possui conteúdos definidos, sendo eles a temporalidade, a localização, o perfil dos personagens e o decurso da ação dramática, onde se tem "o quando (a temporalidade), o onde (a localização), o quem (as personagens) e, finalmente, o qual (a história que vamos contar)". Para a continuidade do relato dessa etapa será utilizado o termo descrição, considerando que "o processo da descrição consiste na elaboração de instrumentos de pesquisa que possibilitem a identificação, o rastreamento, a localização e a utilização de dados" (BELLOTTO, 2006, p. 179) e, assim como no processo de seleção, existem diversas considerações a serem feitas nessa etapa do trabalho.

Em um primeiro momento, tem-se o cuidado de nomear corretamente cada documento, dando-lhe um título que melhor o represente. Isso pode parecer algo óbvio e insignificante, todavia é um passo importante para se ter agilidade no momento da pesquisa. É através do título do documento que, em um primeiro momento, o pesquisador fará seu primeiro filtro.

Após a definição do título, também é necessária a inserção de dados sobre as informações técnicas daquele documento, tais como nome do responsável por sua produção (cinegrafista, repórter, editor etc.), duração do material, tipo de material (colorido, preto e branco), data, local, nome do 
programa (quando tiver), direitos autorais, time code do documento no disco e outros. Posteriormente, tem-se o início da descrição do material referente aquele documento. Em se tratando de programas jornalísticos, as cabeças dos vts ${ }^{4}$ contêm muitas informações relevantes ao entendimento do mesmo, dessa forma, sua descrição também é necessária.

O processo de descrever todo o conteúdo do documento deve ser de forma objetiva e concisa, ou seja, a descrição deve ser da realidade do documento, com um texto claro, evitando palavras poéticas e que nada acrescentam no momento da pesquisa. É importante o estabelecimento de determinadas regras ou padrões para a realização da descrição para evitar que documentos não sejam encontrados em uma busca.

Cabe ressaltar que na descrição dos documentos é importante o olhar atento na identificação de obras arquitetônicas, cidades e principalmente pessoas. A utilização de uma imagem errada pode ocasionar diversos problemas morais e inclusive cabível de processos jurídicos. Por isso, ressaltase mais uma vez, a importância de se inserir metadados no momento em que a imagem está sendo produzida, diminuindo assim as possibilidades de inserção de informações erradas nas sinopses.

Outro aspecto relevante na descrição é a utilização do tipo de imagem existente no documento, se é uma imagem fechada (close), uma vista geral, uma imagem aérea, uma fachada, se é noturna ou diurna, enfim, tudo isso deve ser descrito, ampliando as possibilidades de se atender às imensas especificidades dos usuários, especificidades estas que são infinitamente multiplicadas quando se trata de atender a demandas de usuários da área de esporte. Novamente, ressalta-se que as utilizações dessas palavras na descrição foram adotadas na instituição pesquisada, todavia, não significa que estão de acordo com a terminologia utilizada em documentos de imagens em movimento, existentes na literatura arquivística/biblioteconômica.

\footnotetext{
${ }_{4}^{4}$ Texto que informa o telespectador, durante o telejornal, qual reportagem será exibida a seguir. Contém 0 lead da notícia. Disponível em: <https://www12.senado.leg.br/manualdecomunicacao/glossario/cabeca>. Acesso em: 30 jun. 2016.
} 
Após a descrição, o documento poderá ser indexado. A indexação consiste na utilização de termos que representam aquele documento e que irá possibilitar a recuperação da informação mais eficaz e eficiente.

\subsection{Indexação}

O Dicionário Brasileiro de Terminologia Arquivística define a indexação como "o processo pelo qual documentos ou informações são representados por termos, palavras-chave ou descritores, propiciando a recuperação da informação" (BRASIL, 2004, p. 107). Para que isso se consolide, é necessário que se tenha um vocabulário controlado ou um thesaurus que abranja todas as terminologias da área e este deve ser rigorosamente atualizado, respeitando critérios pré-estabelecidos nas políticas internas da instituição. As principais características que diferenciam um simples vocabulário controlado de um thesaurus são:

1. No thesaurus cada termo corresponde a um conceito. Uma vez aceito, esse termo torna-se um "descritor" ou um "indexador". Caso o termo não seja aceito como "descritor", ele pode ser aceito como "remissivo", isto é, remete para um termo autorizado (descritor).

2. Todos os termos estão relacionados entre si. Nenhum termo pode figurar no thesaurus sem estar relacionado a algum outro, sendo essa relação determinada pelo seu significado.

3. A conceituação dos termos e as relações entre eles são definidas pelo sistema ontológico da área e pelo estudo de cada termo (BRASIL, 2011, online).

Um thesaurus é importante tanto por sua capacidade de organização quanto pelo seu valor didático, isso porque ele "utiliza conceitos específicos da área do conhecimento que contempla e permite, por meio das relações entre os termos, a melhor compreensão da área" (BRASIL, 2011, online).

Apesar da subjetividade do sujeito/profissional que realizará a indexação, ela deverá representar fielmente o documento. A indexação aparece como uma aliada para ampliar a qualidade dos resultados das pesquisas. 


\subsection{Pesquisa/ Recuperação Da Informação}

Todas as ações anteriormente citadas são evidenciadas no momento da pesquisa, ou seja, se a seleção, descrição e indexação forem bem realizadas a pesquisa será eficaz e eficiente.

Como foi dito anteriormente, a recuperação da informação pode ser realizada pela busca livre e pelo vocabulário controlado. A recuperação da informação, no contexto da Ciência da Informação, significa

Para uns, a operação pela qual se seleciona documentos, a partir do acervo, em função da demanda do usuário. Para outros, 'recuperação da informação' consiste no fornecimento, a partir de uma demanda definida pelo usuário, dos elementos de informação documentária correspondente. O termo pode ainda ser empregado para designar a operação que fornece uma resposta mais ou menos elaborada a uma demanda, e esta resposta é convertida num produto cujo formato é acordado com o usuário (bibliografia, nota de síntese, etc.) (FERNEDO, 2003, p. 14).

Nesse sentido, tem-se a busca livre, onde são utilizadas quaisquer palavras que possam representar o assunto desejado, sem nenhum controle, enquanto no vocabulário controlado as palavras utilizadas para a recuperação da informação são inseridas utilizando-se de um conjunto de palavras previamente criadas de acordo com princípios pré-estabelecidos: o thesaurus.

$O$ pesquisador que atua principalmente em arquivos de imagens em movimento, provenientes da televisão, realiza uma série de questionamentos com uma imensa rapidez que são processados internamente em seu cérebro para a escolha do melhor material que será enviado a seu usuário. Lógico que essa tomada de decisão não é fruto de sua imaginação, mas com base nas vivências, não só individuais quanto dos demais profissionais que estão ao seu redor. Para ilustrar, imagine que o usuário solicitou em seu pedido imagens gerais de Belo Horizonte. O primeiro pensamento do pesquisador será o de filtrar pelas imagens brutas, onde as imagens são mais ricas. Em segundo lugar, ele pode optar por imagens aéreas, mais gerais, de pontos turísticos. Em um terceiro momento, verificar se as imagens são diurnas ou noturnas. Esses três cuidados são referentes a uma busca considerada muito simples e são primordiais para disponibilizar o melhor material para o usuário. Quanto mais 
complexa a busca, mais questões são levantadas para alcançar de forma mais eficaz e eficiente os objetivos do usuário.

Além disso, à medida que os usuários vão solicitando suas pesquisas, os profissionais vão aperfeiçoando tanto a seleção, quanto a descrição e indexação. É um fluxo informacional que tem o usuário na parte central. Ao recorrer a documentos de dez anos atrás, por exemplo, nota-se que o número de documentos selecionados era menor, a descrição era superficial e não possuía uma riqueza de detalhes e a indexação não era tão eficiente quanto hoje. Em relação à indexação, houve um grande avanço no software utilizado, a versão antiga permitia somente nove perfis de indexação, hoje esse número é ilimitado, possibilitando a separação mais adequada dos assuntos, principalmente quando referente a documentos maiores, como jogos na íntegra.

Esse aperfeiçoamento das ações realizadas no Cedoc é reflexo do aumento do grau de especificidade dos usuários. Recorre-se principalmente aos pedidos do esporte para ilustrar essa demanda. Os pedidos passaram de uma simples imagem de um determinado jogador fazendo gol para pedidos mais complexos, como por exemplo: um jogador $\mathrm{x}$, fazendo gol no time $\mathrm{x}$, com cabelo da cor $\mathrm{x}$ e comemorando com a dança $\mathrm{x}$. Essa riqueza de detalhes faz com que o trabalho no Cedoc investigado venha sendo aperfeiçoado cada vez mais.

As necessidades dos usuários são variadas, mas Rayo (2004) cita três características comuns a maior parte delas: a rapidez, respostas curtas e acesso fácil ao material. Estas variáveis, ainda segundo a autora, estão condicionadas não apenas à recuperação da informação, como também à realização da seleção. Ou seja, se a seleção ocorre da maneira adequada, as chances dos usuários terem suas necessidades atendidas são ainda maiores.

Uma das principais características do trabalho em uma televisão é a urgência com que normalmente se trabalha, o que faz com que o usuário sempre chegue com pressa ao Centro de Documentação e quer ver seu pedido solucionado o quanto antes. Mas não basta dar uma resposta rápida ao usuário, ela deve ser concisa, ou seja, deve oferecer os melhores e mais adequados materiais em um menor número de documentos possíveis (RAYO, 2004, p. 335, tradução nossa). 
Porém, essa afirmativa não é válida em alguns casos. Pode acontecer do usuário querer um levantamento mais minucioso de todos os materiais existentes sobre um determinado assunto, para uma reportagem especial, por exemplo. Assim, deve sempre haver um diálogo e clareza das necessidades e do deadline deste usuário ao se fazer um pedido no Centro de Documentação.

Partindo dos dados colhidos na pesquisa e seguindo categorias já explicitadas por Rayo, podemos elencar sobre algumas particularidades dos usuários na solicitação de pesquisas de imagens:

- Imagens não específicas: cachorro, dinheiro, pedestre, praças;

- Imagens específicas: cachorro vira-lata, notas de dólar, pedestres caminhando na Praça Sete, praça Raul Soares em Belo Horizonte;

- Acontecimentos não específicos: o usuário solicita a imagem para ilustrar sua produção, sem relação temporal: espetáculo de dança; imagens de Milton Nascimento; gol de Pelé;

- Acontecimentos específicos: primeiro espetáculo de dança do Grupo Corpo, imagens de Milton Nascimento no Clube da Esquina; gol de Pelé na Copa do Mundo de 1970.

Há que se considerar algumas perguntas para atender as demandas desses usuários: quem é? o que pode? como pode? quando? o que realmente necessita? (RAYO, 2004, p. 329). Através dessas perguntas o profissional do Centro de Documentação pode esbarrar em uma outra problemática: os direitos de imagens. Existem muitos casos em que imagens são disponibilizadas somente para um determinado programa e que para serem novamente reutilizadas são necessárias novas permissões, ou simplesmente há recomendações de dar créditos ao cedente. Também existem casos em que as imagens não poderão ser usadas em nenhuma hipótese, cabendo ações jurídicas caso isso ocorra. O pesquisador deve ficar atento a todas essas nuanças antes de disponibilizar o material ao usuário.

Também é importante que as imagens cheguem a esse mesmo usuário com algum tipo de identificação, principalmente quando se tratar de pesquisas maiores, onde há um risco maior de haver confusão sobre qual imagem 
corresponde a cada item da pesquisa. Esse cuidado se dá de duas formas, a primeira é dar nome a cada documento que é enviado ao usuário, ou seja, cada imagem recebe o nome correspondente ao seu conteúdo, a segunda é o envio de uma ficha com o título de cada documento correspondente à ordem em que as imagens foram enviadas. Essa iniciativa evita a confusão no momento em que o editor de imagens do jornalismo irá ilustrar o vt, principalmente quando se tratar de personalidades ou imagens de espetáculos de dança e teatro.

\subsection{Outros Aspectos do Fazer}

Além das ações diárias explícitas até aqui (seleção, descrição, indexação e recuperação), não se pode esquecer que para que o material tenha sempre condições de ser utilizado, faz-se necessário pensar o suporte onde o documento está armazenado, seja ele a película, Umatic, Betacam, Xdcam, servidor e outros. É necessário pensar a longo prazo nos equipamentos que permitem 0 acesso aos documentos armazenados nesses suportes ou a migração de um suporte para outro, considerando que a obsolescência das tecnologias ocorre em uma velocidade cada vez maior.

A palavra acesso possui diversos significados. Segundo Edmondson (2013, p. 78)

Ela designa qualquer forma de utilização das coleções, dos serviços ou dos conhecimentos de um arquivo, notadamente a leitura em tempo real de sons e imagens em movimento e a consulta de fontes de informação sobre o material sonoro e de imagens em movimento, bem como sobre os campos de conhecimento a que se referem. $\mathrm{O}$ acesso pode ter um caráter ativo (de iniciativa da própria instituição) ou passivo (de iniciativa dos usuários da instituição).

No contexto da instituição pesquisada, para garantir o acesso a esses documentos, foi realizada a migração das mídias antigas para outros formatos de armazenamento. Hoje, os documentos são arquivados em discos XDCAM e somente alguns documentos estão em DVD, formato utilizado para a migração das antigas fitas Umatics. Estes materiais também já estão sendo migrados para XDCAM.

Inf. Inf., Londrina, v. 23, n. 2, p. $340-371$, maio/ago. 2018 http://www.uel.br/revistas/informacao 
O acervo do Cedoc é constituído somente por imagens em movimento e os termos de cessão de imagens, com autorizações de personagens e entidades ligadas à construção de determinados vts. Além disso, é de sua responsabilidade cuidar de uma biblioteca de lazer para os funcionários, que inclui livros e filmes. As pautas e demais documentos relacionados a toda a escala de produção das imagens não ficam arquivadas no Cedoc.

Outra questão pertinente é a cessão de imagens. Em um primeiro momento, a guarda das imagens tem como razão primordial sua reutilização pela própria entidade produtora, não podendo ser cedida a terceiros, exceto por algum interesse institucional. Porém, sabe-se que a produção televisiva conta a história da sociedade e do próprio fazer jornalístico. Essas e outras características atraem diversos interessados em ter acesso a esses documentos, tais como pesquisadores, empresas, cineastas e outros. Nesse caso, as imagens podem ser comercializadas e o solicitante deverá utilizá-las somente para o fim pré-estabelecido em contrato.

Como estratégia para se medir a eficiência do Cedoc tem-se utilizado do número de pesquisas realizadas versus o número de pesquisas negativas, mas será que apenas esse aspecto é o suficiente para uma análise aprofundada da questão? Acredita-se que não. Todavia, ficam questionamentos sobre as melhores formas para se obter esses dados.

\section{CONSIDERAÇÕES FINAIS}

Percebe-se que não há uma clareza do por quê o nome Centro de Documentação foi utilizado no momento de sua criação, mas ele está institucionalizado dentro da estrutura organizacional do qual faz parte. Como os Cedocs pesquisados não possuem um registro escrito de sua história de criação, não há indícios de quais critérios foram utilizados para determinada escolha.

Acredita-se na premissa de que os Centros de documentação televisiva analisados possuem em seu acervo coleções, ou seja, um conjunto de imagens agrupadas em função dos interesses da instituição em que estão inseridos. É 
importante salientar que a coleção "[...] não apresenta a organicidade típica dos fundos de arquivo e tem suas peças reunidas artificialmente, de acordo com determinado núcleo de interesse temático" (TESSITORE, 2003, p. 31).

A possível mudança na nomenclatura Cedoc acaba não sendo bem quista principalmente pela possibilidade de 'deixar de ser reconhecido', argumento muito utilizado pelos profissionais da área, que consideram que o nome já está institucionalizado pelos membros da empresa e até mesmo pelo público externo. Dessa forma, faz-se então a necessidade de reflexão da terminologia, do que realmente venha a ser o Cedoc, na tentativa de diminuir essa carência conceitual em que se encontra. Nesse sentido, a Emissora de TV que acolheu a prática da pesquisa objeto deste relato está sofrendo mudanças e o Cedoc está sendo estudado e reestruturado, tanto em relação a processos, quanto à própria nomenclatura, que passará a se denominar Acervo.

O trabalho nos Centros de Documentação de imagens televisivos é um processo contínuo em que não faz sentido se pensarmos separadamente as etapas de seleção, descrição, indexação e pesquisa. Uma se interliga na outra de forma cíclica, num fluxo contínuo, em que o usuário tem um importante papel, está no centro de todo o processo.

Essa estrutura de pensamento remete às características intrínsecas a estas unidades de informação e que independem de sua gestão. Apesar de cada Cedoc possuir aspectos distintos relacionados a cada etapa, seja seleção, descrição, indexação e pesquisa, os processos acontecem nesse fluxo, e o usuário é sempre o foco central. Atender as necessidades de imagens desse usuário é a ideia que norteia a tomada de decisão nesses processos. Pensar nesse fluxo de processo também envolve pensar nas contribuições que a arquivologia pode oferecer para melhor desenvolvimento dessas ações. Em todas as etapas desse fluxo de processos, o usuário tem papel importante. Na seleção, ele é o grande responsável pela produção de imagens, considerando que os principais usuários de todas as instituições pesquisadas são os editores, produtores e repórteres. 
O processo de descrição e indexação também é realizado pensando nas possibilidades de demandas que esses usuários terão no futuro. Uma descrição e indexação bem realizadas são cruciais para a eficaz recuperação desses documentos. E é através das pesquisas que se verifica a amplitude do acervo, considerando que um maior número de pesquisas atendidas positivamente, comprova a eficiência da seleção, indexação e descrição dos documentos.

Considerando todas as questões mencionadas até aqui, apresentam-se a seguir alguns pontos que são essenciais para a criação e o gerenciamento de acervos audiovisuais televisivos:

- Recursos humanos: é indispensável a existência de um profissional capacitado para estar à frente de todos os processos gerenciais que são exigidos nesses espaços. Acreditamos que o profissional bibliotecário ou arquivista são os que mais estão preparados para assumirem essa missão;

- Estrutura física: é crucial um espaço adequado para armazenamento e organização do acervo. $O$ trabalho nesses espaços requer ambiente climatizado para as mídias de armazenamento dos documentos e estruturas adequadas para os funcionários realizarem suas tarefas diárias;

- Organograma institucional: entender a posição no organograma institucional e saber a quem recorrer para tomadas de decisões que envolvem principalmente investimentos financeiros;

- Levantamento dos documentos que ficarão sob responsabilidade do setor, se serão somente os documentos audiovisuais ou também pautas, termos de cessão e outros relacionados à produção das imagens. Importante ressaltar a situação dos documentos que serão armazenados, os tipos de mídias, por exemplo e seu estado de conservação;

- Levantamentos dos possíveis usuários e de suas demandas. Isso implicará na escolha dos softwares;

- Software: a aquisição deve ser feita considerando as especificidades e demandas dos usuários, as características das mídias que irão compor o acervo, se é um acervo analógico, digital ou híbrido; 
- Políticas e diretrizes do fluxo de processos: ter os processos registrados é uma forma de garantir a continuidade dos projetos realizados. Ninguém é eterno em nenhuma instituição, assim, garantir que a tomada de decisão seja realizada com um respaldo formal, possibilita que gerações futuras entendam a formação do acervo e sua evolução;

- Política de cessão de imagens: identificar quem poderá ter acesso ao acervo, como essas imagens poderão ser solicitadas e se haverá cobrança ou não, no caso das empresas privadas;

- Treinamento de pessoal: a formação da equipe exige o cuidado em capacitar a todos para entenderem as especificidades do trabalho em acervo audiovisual televisivo, como a utilização de termos específicos da área de jornalismo.

Estas são algumas das características essenciais para se iniciar o trabalho de organização em um acervo de imagens em movimento no âmbito da televisão. A escolha do nome Centro de Documentação pode ser utilizada para definir esses espaços, considerando que o acervo televisivo apresenta funções no âmbito de arquivo, biblioteca e documento, como mencionamos anteriormente.

O intuito maior dessa pesquisa foi compreender um pouco mais sobre os Centros de Documentação responsáveis por armazenar o acervo de imagens em movimento provenientes do âmbito televisivo. As visitas e entrevistas foram inspiradoras, mesmo com algumas limitações existentes nos Cedocs foi possível perceber que o trabalho diário vem sendo desenvolvido com prazer e dedicação.

A preocupação maior é a preservação e garantia do acesso, mesmo compreendendo que em um primeiro momento a preservação do acervo de imagens em movimento como memória não é o foco principal dos Cedocs pesquisados. Seu valor inicial, ou valor primário, visa atender a demanda da instituição, do órgão produtor.

Percebe-se, portanto, que a arquivologia tem muito a contribuir para o desenvolvimento do trabalho nos Cedocs pesquisados. Dessa forma, ressaltase a importância dos profissionais que atuam nesses espaços buscar 
compreender melhor essas possibilidades, tornando-as fontes de aperfeiçoamento do trabalho que já realizam.

\section{REFERÊNCIAS}

ALVES, C. A.; DUARTE, E. N. A relação entre a ciência da informação e a ciência da administração. Transinformação, Campinas, v. 27, n. 1, jan./abr. 2015. Disponível em: <http://www.scielo.br/scielo.php?pid=S0103-

37862015000100037\&script=sci_arttext\&tlng=pt>. Acesso em: 05 maio 2016.

BELLOTTO, H. L. Arquivos permanentes: tratamento documental. 4. ed. Rio de Janeiro: Editora FGV, 2006. 318 p.

BRASIL. Arquivo Nacional. Dicionário Brasileiro de Terminologia

Arquivística. Rio de Janeiro: Arquivo Nacional, 2004. 231 p. Disponível em: $<$ http://www.arquivonacional.gov.br/images/pdf/Dicion_Term_Arquiv.pdf >. Acesso em: 11 maio 2016.

BRASIL. Instituto Nacional de Estudos e Pesquisas Educacionais Anísio Teixeira (INEP). O que é um thesaurus. Brasília: Instituto Nacional de Estudos e Pesquisas Educacionais Anísio Teixeira, 2011. Disponível em: <http://portal.inep.gov.br/o-que-e-o-thesaurus>. Acesso em: 15 jun. 2016.

COMPARATO, D. Da criação ao roteiro. Rio de Janeiro: Rocco, 2000. 486 p.

EDMONDSON, R. Filosofia e princípios da arquivística audiovisual. Rio de Janeiro: Associação Brasileira de Preservação Audiovisual/Cinemateca do Museu de Arte Moderna do Rio de Janeiro, 2013. 224 p.

FEDERAÇÃO INTERNACIONAL DE ARQUIVOS DE TELEVISÃO (FIAT). Disponível em: <http://fiatifta.org/index.php/2016/05/03/call-for-presentationfiatifta-world-conference-2016/>. Acesso em: 07 maio 2016.

FEDERAÇÃO INTERNACIONAL DE ARQUIVOS FÍLMICOS (FIAF). Disponível em: <http://www.fiafnet.org/pages/Community/Mission-FIAF.html>. Acesso em: 09 maio 2016.

FERNEDO, E. Recuperação da informação: análise sobre a contribuição da Ciência da Computação para a Ciência da Informação. 2003. 137 f. Tese (Doutorado em Ciências da Comunicação) - Universidade de São Paulo, Escola de Comunicação e Artes, São Paulo, 2003. Disponível em: $<$ http://www.teses.usp.br/teses/disponiveis/27/27143/tde-15032004-130230/ptbr.php>. Acesso em: 02 jun. 2016. 
LOPES, A. de Q. Reflexões arquivísticas no processo de gestão de documentos de imagens em movimento produzidos e/ou recolhidos em virtude da atividade fim de uma emissora de televisão. 2016. $109 \mathrm{f}$. Dissertação (Mestrado em Ciência da Informação) - Universidade Federal de Minas Gerais, Escola de Ciência da Informação, Belo Horizonte, 2016.

RAYO, M. I. G. La selección del material audiovisual de televisión. 2004. 384 f. Tese (Doutorado em Documentação) - Universidad Carlos III de Madrid, Departamento de Biblioteconomía y Documentación, Madrid, 2004.

ROUSSEAU, Jean-Yves; COUTURE, C. Os fundamentos da disciplina arquivística. Lisboa: Dom Quixote, 1998. 360 p.

SCHELLENBERG, T. R. Arquivos modernos: princípios e técnicas. 6. ed. Rio de Janeiro: Editora FVG, 2006. 386 p.

TESSITORE, V. Como implantar centros de documentação. São Paulo: Arquivo do Estado/Imprensa Oficial do Estado de São Paulo, 2003. 52 p.

UNESCO. Recomendación sobre la Salvaguardia y la Conservación de las Imágenes en Movimiento. 1980. Disponível em:

$<$ http://portal.unesco.org/es/ev.phpURL ID $=13139 \& U R L$ DO=DO_TOPIC\&URL_SECTION=201.html>. Acesso em: 05 mar. 2016.

\title{
A TELEVISION STATION MANAGEMENT PROCESS OF MOVING IMAGE DOCUMENTS
}

\begin{abstract}
Introduction: The television images collections are organized and stored in documentation centers, image banks or image archives. Manage images, making them readily available to their internal users, reporters or television programs producers, is an activity that requires increasingly specificity and which is challenging professionals. Objective: investigate how the work in a moving image documentation center is being done. Methodology: Relating the empirical doing with the theory, in order to seek reflections and contributions for the improvement of the processes, having as reference the participant observation in the center of documentation of moving images of the XXXXXX Television Network, branch Belo Horizonte, Minas Gerais, Brazil. Results: From the data collected, it was observed that there was no consensus in the nomenclature adopted for the sector, as well as in the selection of the professional who works there. Conclusions: To the processes investigated during the participant observation, we consider that the work in the image documentation center is a continuous process and that it does not make sense to think separately the steps of selection, description, indexation and research, supported by the archival theory.
\end{abstract}

Descriptors: Documentation centers. Moving image archive. Television archive.

Inf. Inf., Londrina, v. 23, n. 2, p. $340-371$, maio/ago. 2018

http://www.uel.br/revistas/informacao 


\title{
EL PROCESO DE GESTIÓN DE DOCUMENTOS DE IMÁGENES EN MOVIMIENTO DE UNA CADENA DE TELEVISIÓN
}

\begin{abstract}
RESUMEN
Introducción: Los acervos de imágenes televisivas son ordenados y almacenados en centros de documentación, bancos o archivos de imágenes. Gestionar estos datos para una rápida disponibilidad a sus usuarios directos, reporteros o productores de programas televisivos, es una actividad que necesita modos específicos de utilización, desafiando a los profesionales del área. Objetivo: El reto de esta investigación fue registrarla labor en un centro de documentación de imágenes en movimiento. Metodología: relacionando la teoría con el hecho empírico se buscan reflexiones y contribuciones para perfeccionar las fases del trabajo, con referencia a la observación participante en dicho centro de la Cadena XXXXXX de Televisión, con filial en Belo Horizonte, Minas Gerais, Brasil. Resultados: A partir de la recogida de datos, se verificó que no hay consenso en la nomenclatura que se adopta en el sector y en la selección de los profesionales actuantes. Conclusiones: Consideramos que el trabajo en el centro de documentación de imágenes es un proceso continuo. Sin embargo, la separación de las etapas de selección, descripción, indexación e investigación, amparadas por la teoría archivística, no sería necesaria.
\end{abstract}

Descriptores: Centro de documentación. Archivo de imagenes em movimiento. Archivo de televisión.

Recebido: 10.03. 2017

Aceito: 27.02.2018 